\title{
Isotermas de adsorção e calor isostérico da palma forrageira enriquecida proteicamente
}

\author{
Ana R. N. Campos ${ }^{1}$, Flávio L. H. da Silva ${ }^{1}$, Josivanda P. Gomes ${ }^{2}$, Líbia S. C. 0 liveira ${ }^{1} \&$ Marinévea M. 0 liveira $^{3}$
}

\section{RESU MO}

0 enriquecimento protéico da palma forrageira através de fermentação semissólida com a utilização de leveduras visou aumentar o valor nutricional dessa forragem a fim de que possa ser utilizada como suplemento protéico para ração animal, que poderá ser oferecida ainda úmida ou ser secada e armazenada sob condições adequadas. 0 presente trabalho foi realizado com o objetivo de estudar as isotermas de adsorção da palma forrageira enriquecida proteicamente, nas temperaturas de 30,35 e $40^{\circ} \mathrm{C}$, escol her o modelo matemático que melhor se ajusta aos dados experimentais e determinar 0 calor isostérico de adsorção, buscando-se parâmetros para o estudo do armazenamento deste material. A partir dos resultados obtidos verificou-se que o modelo de Henderson foi o que melhor se ajustou aos dados experimentais das isotermas de adsorção nas três temperaturas estudadas e que o calor isostérico de adsorção do produto diminui com 0 aumento da umidade de equilíbrio. Para o armazenamento da palma enriquecida é necessário que a faixa ideal de atividade de água esteja compreendida entre 0,25-0,35, que corresponde a uma umidade (b.s.) menor que 0,03 eliminando, desta forma, qualquer crescimento de micro-organismos.

Palavras-chave: atividade de água, fermentação semissólida, levedura, O puntia ficus-indica Mill

\section{Adsorption isotherms and heat isosteric of protein enriched cactus pear}

\begin{abstract}
The protein enrichment of cactus pear through solid-state fermentation with the use of yeasts sought to increase the nutritional value of this forage so that it may be used as protein supplement for animal feed which may be offered either wet or dried and stored under appropriate conditions. The present work had its objective to study the adsorption isotherms of the protein enriched cactus pear, at temperatures of 30,35 and $40^{\circ} \mathrm{C}$, to choose the mathematical model that best adjusted to experimental data and to determine the adsorption heat isosteric, looking for parameters for study of storage of this material. Starting from the obtained results, it was verified that the Henderson model was better if it was adjusted to experimental data adsorption isotherms at the three studied temperatures and that adsorption heat isosteric of studied product decreases with the increase of moisture content. For the storage of the enriched cactus pear it is necessary that the ideal range of activity of water should be between $0.25-0.35$, which corresponds to moisture content (d.b.) smaller than 0.03 , eliminating, this way, any growth of microorganisms.
\end{abstract}

Key words: water activity, solid state fermentation, yeast, O puntia ficus-indica Mill

\footnotetext{
1 UAEQ/UFCG, Av. A prígio Veloso, 882, Bairro Universitário, Campina Grande, PB. Fone: (83) 3310-1521. E-mail: arncampos@yahoo.com.br; flavioluizh@yahoo.com.br libiac@deq.ufcg.edu.br

2 UAEA/U FCG. Fone: (83) 3310-1185. E-mail: josi@deag.ufcg.edu.br

EM EPA, Estrada de Imbaúba, km 3, Zona Rural, CEP 58117-000, Lagoa Seca, PB. Fone: (83) 3366-1298. E-mail: marinevea@hotmail.com
} 


\section{INTRODUÇÃO}

Os períodos de seca e as incertezas climáticas frequentes na região semiárida do Nordeste do Brasil constituem fatores limitantes à produção animal. Devido as suas características as cactáceas, dentre as quais de destaca a palma forrageira (Opuntia ficus-indica Mill), representam fonte de água e alternativa alimentar para as regiões subúmidas e semiáridas (Cavalcante \& Cândido, 2003).

Bem adaptada morfo fisiologicamente às condições adversas do semiárido, a palma possui grande quantidade de água, é rica em resíduos minerais como cálcio, magnésio, sódio e potássio e vitaminas A, C e do complexo B (Batista Filho, 2005). Apresenta elevado teor de carboidratos solúveis, além de alto coeficiente de digestibilidade da matéria seca (Santos et al., 1992; Teixeira et al., 1999); contudo, o baixo teor de matéria seca, fibras e proteína bruta, precisam ser considerados quando se utiliza essa forrageira como principal ingrediente nas dietas animais em função de serem observados perda de peso, baixo desempenho, distúrbios metabólicos, especialmente diarréias e redução no teor de gordura do leite (Perazzo Neto, 1999; Santos et al., 1997; 1990).

$\mathrm{Na}$ tentativa de contribuir para o desenvolvimento sustentável da região, estudaram-se formas alternativas de aumentar o valor nutricional dessa fonte forrageira através de um processo de enriquecimento protéico utilizando-se a levedura Saccharomyces cerevisiae. A palma enriquecida proteicamente poderá ser utilizada como suplemento protéico para ração animal e oferecida, ainda úmida, logo após o enriquecimento ou, ainda, ser secada e armazenada sob condições adequadas e só então oferecida aos animais, principalmente na época da estiagem.

Segundo Wang \& Brennan (1991) e Sopade \& Ajisegiri (1994) o conhecimento do calor isostérico em função da umidade de equilíbrio é essencial nos estudos de secagem e armazenamento de produtos agrícolas, servindo para estimar as necessidades energéticas do processo de secagem fornecendo, também, dados sobre o estado da água no produto.

Este trabalho foi desenvolvido para determinar as isotermas de adsorção da palma forrageira enriquecida proteicamente, nas temperaturas de 30,35 e $40{ }^{\circ} \mathrm{C}$, definir o modelo matemático que melhor se ajusta aos dados experimentais e determinar o calor isostérico de adsorção, buscando-se parâmetros para o estudo do armazenamento deste material.

\section{MATERIAL E MÉTODOS}

Os experimentos foram realizados no Laboratório de Transferência em Meios Porosos e Sistemas Particulados da Unidade Acadêmica de Engenharia Química da Universidade Federal de Campina Grande, Paraíba.

Depois de enriquecida proteicamente, através de uma fermentação semissólida em que se utilizou a levedura Saccharomyces cerevisiae, a palma forrageira foi colocada em estufa de circulação de ar forçado a temperatura de $55^{\circ} \mathrm{C}$, por três dias, tempo em que se observou completa secagem do material e, em seguida, processada em moinho de facas da marca Tecnal. A temperatura de $55^{\circ} \mathrm{C}$ foi escolhida para evitar perdas por volatilização ou a alteração de outros nutrientes, principalmente compostos nitrogenados, conforme Araújo et al. (2005).

Para o levantamento dos dados das isotermas de adsorção da palma forrageira enriquecida utilizou-se o equipamento Termoconstanter Novasina TH 200. Individualmente, diferentes quantidades de água destilada eram adicionadas a $10 \mathrm{~g}$ de amostra seca, entre 0,5-5,0 mL, de maneira a se obter uma faixa de umidade adequada para esse estudo; $12 \mathrm{~h}$ depois se determinou o valor da atividade de água das amostras.

Amostras de 2,0 g, em duplicata, foram colocadas em células plásticas que acompanham o equipamento. As células, já contendo as amostras, foram levadas ao equipamento para determinação da atividade de água $\left(\mathrm{a}_{\mathrm{w}}\right)$ nas temperaturas de 30,35 e $40{ }^{\circ} \mathrm{C}$; a amostra permanecia no equipamento até que a leitura da atividade de água se estabilizasse; em seguida, era retirada, pesada em balança analítica e posta na estufa, processo que se repetiu com as diferentes amostras. Cada leitura obtida para cada temperatura correspondia a um ponto da curva da isoterma de adsorção; no final, cada amostra foi levada à estufa, a $105^{\circ} \mathrm{C}$, durante $24 \mathrm{~h}$, para determinação da massa seca (AOAC, 1990).

Calculou-se a umidade de equilíbrio $\left(\mathrm{X}_{\mathrm{eq}}\right)$ pela diferença entre a massa que a amostra apresentou no equilíbrio e sua massa seca, conforme Eq. 1:

$$
\mathrm{X}_{\mathrm{eq}}=\frac{\mathrm{m}_{\mathrm{eq}}-\mathrm{m}_{\mathrm{s}}}{\mathrm{m}_{\mathrm{s}}}
$$

em que:

$$
\begin{aligned}
& \mathrm{X}_{\mathrm{eq}} \text { - umidade de equilíbrio, b.s. } \\
& \mathrm{m}_{\mathrm{eq}} \text { - massa da amostra no equilíbrio, } \mathrm{g} \\
& \mathrm{m}_{\mathrm{s}}-\text { massa da amostra seca, } \mathrm{g}
\end{aligned}
$$

Vários modelos matemáticos propostos na literatura foram testados para correlacionar a umidade de equilíbrio e a atividade de água e três modelos foram selecionados para representar os dados experimentais das curvas de adsorção da palma forrageira enriquecida proteicamente. As equações selecionadas estão apresentadas na Tabela 1.

Tabela 1. Modelos matemáticos usados para descrever as curvas de adsorção da palma forrageira enriquecida proteicamente

\begin{tabular}{ccc}
\hline Nome do modelo & Equação do modelo & Referência \\
BET & $\mathrm{X}_{\mathrm{eq}}=\frac{\mathrm{X}_{\mathrm{m}} \mathrm{Ca} \mathrm{a}_{\mathrm{w}}}{1 \mathrm{a}_{\mathrm{w}}} \frac{1(\mathrm{n}+1)\left(\mathrm{a}_{\mathrm{w}}\right)^{\mathrm{n}}+\mathrm{n}\left(\mathrm{a}_{\mathrm{w}}\right)^{\mathrm{n} 1}}{1(1-\mathrm{C}) \mathrm{a}_{\mathrm{w}} \mathrm{C}\left(\mathrm{a}_{\mathrm{w}}\right)^{n-1}}$ & Brunauer et al. (1938) \\
GAB & $\mathrm{X}_{\mathrm{cq}}=\frac{\mathrm{X}_{\mathrm{m}} C K \mathrm{a}_{\mathrm{w}}}{\left(1-\mathrm{Ka}_{\mathrm{w}}\right)\left(1-\mathrm{Ka}_{\mathrm{w}}+\mathrm{CKa} \mathrm{a}_{\mathrm{w}}\right)}$ & van den Berg (1985) \\
Henderson & $\mathrm{X}_{\mathrm{eq}}=\left[\frac{-\ln \left(1-\mathrm{a}_{\mathrm{w}}\right)}{\mathrm{b}}\right]^{1 / \mathrm{a}}$ & Henderson (1952) \\
\hline
\end{tabular}

em que:

$\mathrm{a}_{\mathrm{w}}$ - atividade de água, decimal

$\mathrm{x}_{\mathrm{m}}$ - conteúdo de umidade na monocamada molecu- 
lar, decimal

$\mathrm{C}$ - constante de BET relacionada ao calor de sorção da camada molecular

$\mathrm{n}$ - número de camadas moleculares

a, b e K - parâmetros de ajuste

Os parâmetros dos modelos matemáticos estudados foram calculados por meio de regressão não-linear dos dados experimentais, pelo método Quasi-Newton, utilizando-se o programa computacional Statistica 5.0.

Avaliou-se o grau de ajuste dos modelos matemáticos aos dados experimentais, através do coeficiente de determinação $\left(\mathrm{R}^{2}\right)$, do desvio médio relativo $(\mathrm{P})$ e do comportamento da distribuição dos valores residuais. O desvio médio relativo é definido, conforme Eq. 2.

$$
P(\%)=\frac{100}{N} \sum_{i=1}^{N} \frac{\left|V_{\text {exp }}-V_{p}\right|}{V_{\text {exp }}}
$$

em que:

$\mathrm{V}_{\text {exp }}$ - valores experimentais

$\mathrm{V}_{\mathrm{p}}$ - preditos da umidade de equilíbrio

$\mathrm{N}$ - número de dados experimentais

Um modelo é considerado aceitável quando o valor de $\mathrm{R}^{2}$ for próximo da unidade e o valor de $\mathrm{P}$ for menor que 10 (Barros Neto et al., 1995; Lomauro et al., 1985).

$\mathrm{O}$ calor isostérico de adsorção $\mathrm{Q}_{\mathrm{st}}\left(\mathrm{kJ} \mathrm{kg}^{-1}\right)$ foi determinado pela equação de Clausius-Clapeyron, Eq. 3 (Kechaou \& Maalej, 1999):

$$
\Delta \mathrm{Q}_{\mathrm{st}}=-\mathrm{R}\left(\frac{\partial\left(\ln \mathrm{a}_{\mathrm{w}}\right)}{\partial(1 / \mathrm{T})}\right) \sqrt{\mathrm{a}^{2}+\mathrm{b}^{2}}
$$

em que:

$\mathrm{R}$ - constante universal dos gases $\left[0,4618 \mathrm{~kJ}(\mathrm{~kg} \mathrm{~K})^{-1}\right]$ $\mathrm{a}_{\mathrm{w}}$ - atividade de água

$\mathrm{T}$ - temperatura absoluta, em $\mathrm{K}$

Para predizer o comportamento do calor de adsorção em função da umidade de equilíbrio, utilizou-se o modelo exponencial de Tolaba \& Suaréz (1995), conforme a Eq. 4.

$$
\mathrm{Qst}=\mathrm{A}+\mathrm{B}^{\left(-\mathrm{X}_{\mathrm{eq}} \mathrm{C}\right)}
$$

em que: A, B e C: parâmetros de ajuste do modelo

\section{RESULTADOS E DISCUSSÃO}

Os dados obtidos experimentalmente da atividade de água $\left(\mathrm{a}_{\mathrm{w}}\right)$ com suas respectivas umidades de equilíbrio $\left(\mathrm{X}_{\mathrm{eq}}\right)$ em diferentes temperaturas, estão apresentados na Tabela 2.

Observa-se através dos valores da Tabela 2, que os pontos experimentais das isotermas de adsorção estão praticamente alinhados nas três temperaturas estudadas; verificouse, desta forma, pouco efeito da temperatura sobre as isotermas, fato que pode ser justificado pela pequena variação nos níveis de temperatura estudada $\left(30,35\right.$ e $\left.40{ }^{\circ} \mathrm{C}\right)$; essas temperaturas se aproximam da temperatura média anual encontrada na região semiárida do Nordeste brasileiro.

\begin{tabular}{|c|c|c|c|c|c|}
\hline \multicolumn{6}{|c|}{ Temperatura $\left({ }^{\circ} \mathrm{C}\right)$} \\
\hline \multicolumn{2}{|c|}{30} & \multicolumn{2}{|c|}{35} & \multicolumn{2}{|c|}{40} \\
\hline$a_{w}$ & $X_{\text {eq }}$ & $a_{w}$ & $X_{\text {eq }}$ & $a_{w}$ & $x_{\text {eq }}$ \\
\hline 0 & 0 & 0 & 0 & 0 & 0 \\
\hline 0,390 & 0,0331 & 0,406 & 0,0348 & 0,409 & 0,0333 \\
\hline 0,523 & 0,0606 & 0,521 & 0,0488 & 0,511 & 0,0562 \\
\hline 0,615 & 0,0802 & 0,607 & 0,0790 & 0,596 & 0,0579 \\
\hline 0,651 & 0,0926 & 0,662 & 0,0896 & 0,643 & 0,0766 \\
\hline 0,748 & 0,1143 & 0,737 & 0,1080 & 0,734 & 0,0898 \\
\hline 0,774 & 0,1180 & 0,785 & 0,1238 & 0,769 & 0,1195 \\
\hline 0,819 & 0,1621 & 0,806 & 0,1546 & 0,830 & 0,1523 \\
\hline 0,865 & 0,1965 & 0,863 & 0,1730 & 0,867 & 0,1853 \\
\hline 0,884 & 0,2409 & 0,875 & 0,1980 & 0,869 & 0,1831 \\
\hline 0,898 & 0,2085 & 0,920 & 0,2103 & 0,887 & 0,2268 \\
\hline
\end{tabular}

Tabela 2. Valores de atividade de água $\left(a_{w}\right)$ e umidade de equilíbrio $\left(X_{\text {eq }}\right)$ da palma forrageira enriquecida para as diferentes temperaturas

Em geral, na Tabela 2 a umidade de equilíbrio diminui com o aumento da temperatura. A diminuição da umidade de equilíbrio com o aumento da temperatura pode ser justificada com base no aumento da pressão de vapor da água no ar e na superfície do produto. Este aumento é maior na superfície do produto visto que a mesma apresenta maior número de moléculas de água que o ar. Maior pressão de vapor implica em maior perda de água, para que se atinja o equilíbrio (Ferreira \& Pena, 2003). Kechaou \& Maalej (1999) ao estudarem as características de dessorção do algodão herbáceo e de banana em temperaturas de 20 a $80{ }^{\circ} \mathrm{C}$ observaram uma pequena diminuição da umidade de equilíbrio com o aumento da temperatura. Segundo esses autores, tal fato pode ser explicado em virtude da dissolução dos açúcares da fruta, o que aumenta significativamente quando a temperatura também aumenta. Gabas (1998) e Adam et al. (2000) obtiveram resultados equivalentes em estudo sobre as isotermas de 20 a $80^{\circ} \mathrm{C}$ de uva e cebola, respectivamente.

Apresentam-se, na Tabela 3, os parâmetros dos modelos, os coeficientes de determinação $\left(\mathrm{R}^{2}\right)$, o desvio médio relativo $(\mathrm{P})$ e a análise de distribuição dos resíduos para o ajuste aos dados experimentais das isotermas da palma forrageira enriquecida proteicamente nas três temperaturas estudadas. Analisando-se os dados da Tabela 3 verifica-se, para o modelo de GAB, que o valor do parâmetro $X_{m}$ aumenta quando a temperatura é elevada para $35^{\circ} \mathrm{C}$ e diminui com o progressivo aumento da temperatura, o valor de $\mathrm{C}$ diminui quando a temperatura é aumentada de 30 para $35^{\circ} \mathrm{C}$ e aumenta quando passa de 35 para $40{ }^{\circ} \mathrm{C}$. Para o modelo de $\mathrm{BET}$, o valor de $\mathrm{X}_{\mathrm{m}}$ diminui com o aumento da temperatura e, em seguida, aumenta quando a temperatura é elevada para $40{ }^{\circ} \mathrm{C}$, o valor de $\mathrm{C}$ aumenta e em seguida diminui com o progressivo aumento da temperatura; assim, os valores do conteúdo de umidade na monocamada molecular $\left(\mathrm{X}_{\mathrm{m}}\right)$ e da constante de BET relacionada ao calor de sorção da camada molecular (C) das equações de BET e GAB, apresentaram comportamentos contrários; no entanto, não se observou tendência desses parâmetros em relação à temperatura, mas, discreta mudança nos valores dos parâmetros a e b com o aumento da temperatura, deduzindo-se, então, que não houve, praticamente, influência da temperatura sobre os parâmetros 
Tabela 3. Parâmetros estimados, valor de $R^{2}$, P e comportamento da distribuição dos resíduos para as diferentes equações estudadas

\begin{tabular}{|c|c|c|c|c|c|c|c|}
\hline \multirow{2}{*}{ Modelo } & \multirow{2}{*}{$\begin{array}{c}\mathrm{T} \\
\left({ }^{\circ} \mathrm{C}\right)\end{array}$} & \multicolumn{3}{|c|}{ Parâmetros } & \multirow{2}{*}{$\mathbf{R}^{2}$} & \multirow{2}{*}{ P (\%) } & \multirow{2}{*}{$\begin{array}{r}\text { Distribuição } \\
\text { dos resíduos }\end{array}$} \\
\hline & & $X_{m}$ & C & K & & & \\
\hline \multirow{3}{*}{ GAB } & 30 & 0,053 & 1,571 & 0,893 & 0,982 & 6,40 & \multirow{3}{*}{ Tendencioso } \\
\hline & 35 & 0,139 & 0,548 & 0,723 & 0,991 & 5,26 & \\
\hline & 40 & 0,028 & 6,319 & 0,984 & 0,996 & 6,18 & \\
\hline \multirow{4}{*}{ BET } & & $X_{m}$ & $\mathrm{C}$ & $n$ & & & \multirow{4}{*}{ Aleatório } \\
\hline & 30 & 0,241 & 0,104 & 5,739 & 0,974 & 10,88 & \\
\hline & 35 & 0,035 & 2,719 & 14,99 & 0,992 & 5,89 & \\
\hline & 40 & 0,367 & 0,055 & 5,879 & 0,980 & 11,12 & \\
\hline \multirow{4}{*}{ Henderson } & & $a$ & b & & & & \multirow{4}{*}{ Aleatório } \\
\hline & 30 & 7,652 & 0,815 & & 0,992 & 5,84 & \\
\hline & 35 & 8,513 & 0,838 & & 0,992 & 5,60 & \\
\hline & 40 & 7,674 & 0,783 & & 0,988 & 5,77 & \\
\hline
\end{tabular}

a e b do modelo de Henderson.

De acordo com os resultados dos valores do coeficiente de determinação $\left(\mathrm{R}^{2}\right)$ e do erro médio relativo $(\mathrm{P})$, o modelo de Henderson descreveu melhor as isotermas de adsorção da palma forrageira enriquecida proteicamente, nas três temperaturas estudadas.

Para o armazenamento da palma forrageira enriquecida proteicamente não se utilizando aditivos nem refrigeração, é necessário que a faixa ideal de atividade de água residual esteja compreendida entre 0,25-0,35 (Araújo et al., 2005). Utilizando-se do modelo de Henderson para obter informações sob as condições de armazenamento do material enriquecido, vê-se que esta faixa de $\mathrm{a}_{\mathrm{w}}$ corresponde a uma umidade (base seca) menor que 0,03 eliminando, desta forma, qualquer crescimento de micro-organismos.

A Figura 1A, B e C representa, graficamente, a relação entre a atividade de água $\left(\mathrm{a}_{\mathrm{w}}\right)$ e a umidade de equilíbrio $\left(\mathrm{X}_{\mathrm{eq}}\right)$, nas temperaturas de 30,35 e $40^{\circ} \mathrm{C}$, respectivamente, ajustadas pelas equações de GAB, BET e Henderson.

Na Figura 1A e C, o modelo de BET não se ajustou bem aos dados das isotermas de 30 e $40{ }^{\circ} \mathrm{C}$ para valores de atividade de água baixos; nota-se, na Figura 2B, bom ajuste dos modelos aos dados das isotermas de $35^{\circ} \mathrm{C}$ em toda a faixa de atividade de água estudada, sendo o modelo de Henderson, apesar de bi-paramétrico, o que melhor se ajustou aos dados das três isotermas.

As isotermas de adsorção da palma forrageira enriquecida proteicamente nas temperaturas estudadas, podem ser classificadas como do tipo III. Park \& Nogueira (1992) definem este tipo de isoterma segundo a classificação de $\mathrm{BET}$, quando sua forma tem aparência da letra J. Blahovec (2004) estudou alguns modelos de isotermas de sorção realizando um estudo matemático sobre os valores aceitáveis para cada parâmetro. Para o modelo de GAB e para as curvas do tipo III este autor afirma que $0<\mathrm{K} \leq 1$ e $0 \leq \mathrm{C} \leq 2$. Observando-se os parâmetros do modelo de GAB (Tabela 3) verifica-se, para as isotermas de 30 e $35^{\circ} \mathrm{C}$, que os valores de $\mathrm{K}$ estão entre 0,723 e 0,893 e os de $\mathrm{C}$ são menores que 2 tendo-se, assim, a confirmação matemática do tipo de isotermas obtidas neste estudo. Esta forma é típica de produtos com altas concentrações de açúcares e solutos e que apresentam pouca adsorção por capilaridade. Constata-se
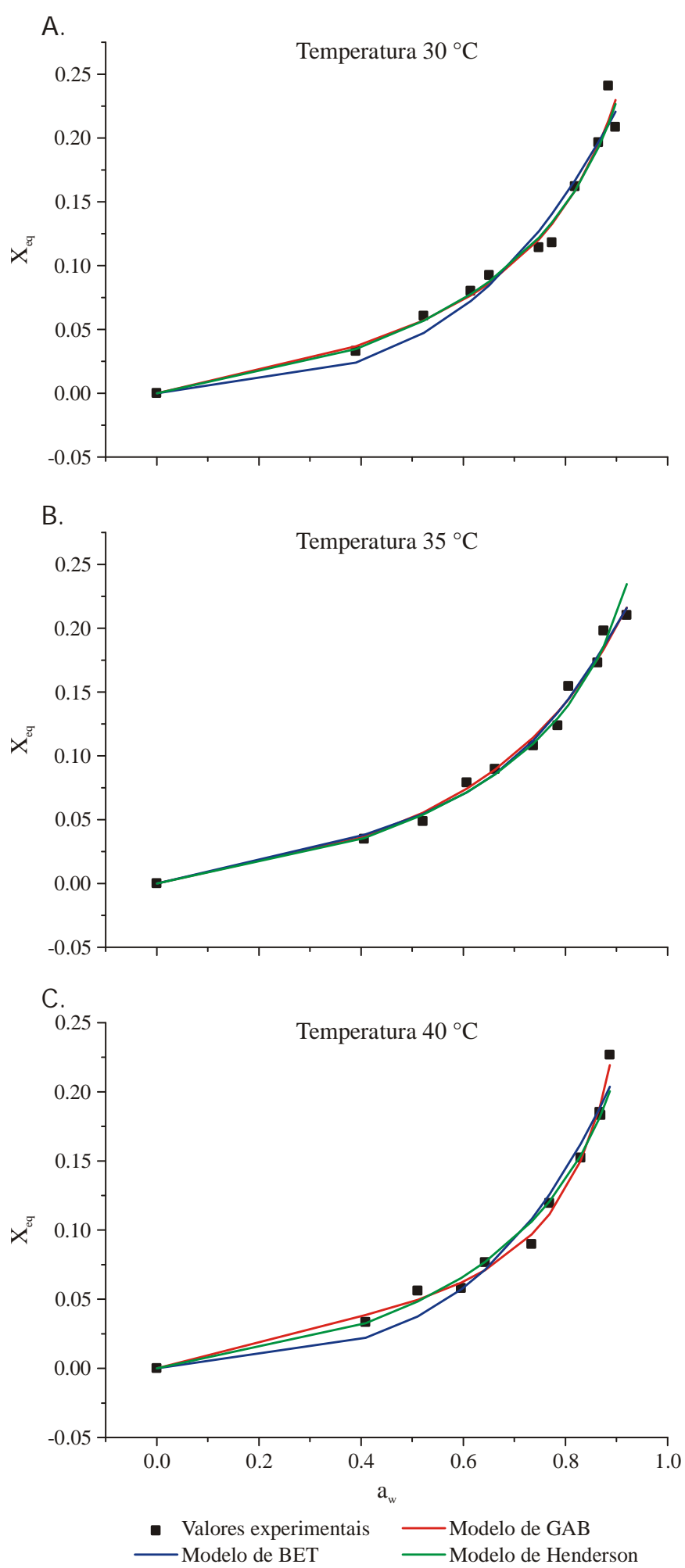

Figura 1. Isotermas de adsorção da palma forrageira enriquecida proteicamente nas temperaturas de $30(A), 35$ (B) e $40^{\circ} \mathrm{C}$ (C) ajustadas pelos modelos matemáticos de GAB, BET e Henderson

que, mesmo se usando critérios diferentes para a classificação das isotermas, os resultados são concordantes entre os autores.

Os resíduos baseados nas diferenças entre os valores experimentais e calculados para cada modelo matemático analisado são apresentados na Figura 2A, B e C, na qual se ve- 
A.



B.



C.

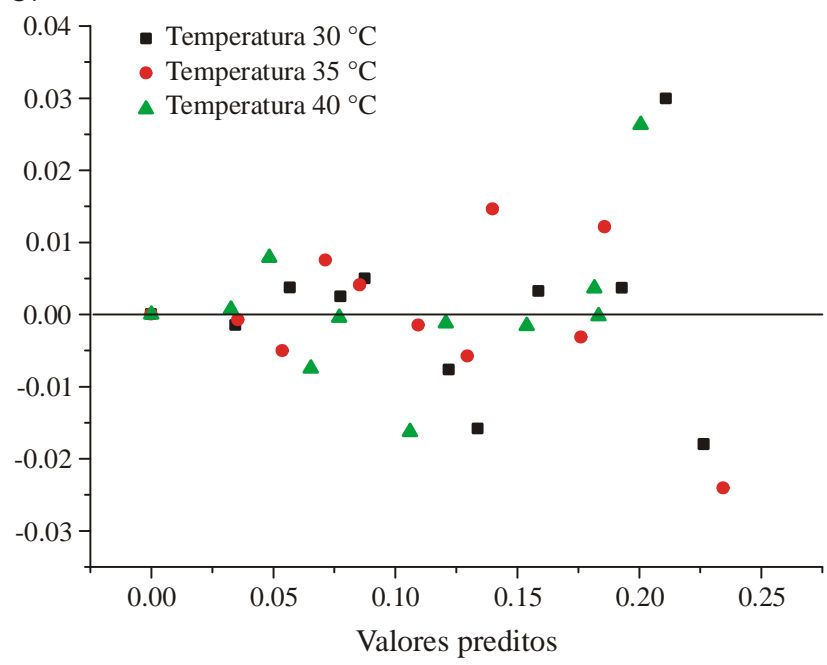

Figura 2. Distribuição dos resíduos para o modelo de GAB (A), BET (B) e Henderson $(C)$, em função dos valores preditos

rificou que a distribuição dos resíduos para os modelos de BET e Henderson (Figura 2B e C) indicou comportamento aleatório, mostrando tratar-se de modelos apropriados para a descrição das isotermas da palma forrageira enriquecida proteicamente, nas temperaturas de 30,35 e $40{ }^{\circ} \mathrm{C}$, porém para o modelo de GAB (Figura 2A) se observou uma distribuição tendenciosa dos resíduos sugerindo que a equação que descreve este modelo representa, de forma menos satisfatória, o fenômeno estudado.

Em resumo, pode-se dizer que todos os modelos testados representaram, razoavelmente bem as isotermas de adsorção da palma forrageira enriquecida proteicamente, em que o modelo de Henderson representou o melhor ajuste.

A curva isostérica de adsorção ( $\operatorname{Ln}\left[\mathrm{a}_{\mathrm{w}}\right]$ em função de 1/T) (Figura 3), para as várias condições de umidade de equilíbrio das amostras, foi obtida com base nos dados das curvas de equilíbrio higroscópico, ajustadas pelo modelo de Henderson. O valor do calor isostérico para cada conteúdo de umidade corresponde ao valor do coeficiente de inclinação da reta (Figura 4), multiplicado pela constante universal dos gases que é dada por $\mathrm{R}=0,4618 \mathrm{~kJ}\left(\mathrm{~K} \mathrm{~kg} \mathrm{H}_{2} \mathrm{O}\right)^{-1}$, conforme propõe a equação de Clausius-Clapeyron. Os dados referentes à inclinação das retas, coeficiente de determinação $\left(\mathrm{R}^{2}\right)$ e calor isostérico de adsorção $\left(\mathrm{Q}_{\mathrm{st}}\right)$ para os diferentes valores de umidade de equilíbrio $\left(\mathrm{X}_{\text {eq }}\right)$ estão apresentados na Tabela 4.

Observando-se os dados da Tabela 4, nota-se decréscimo do calor isostérico de sorção $\left(\mathrm{Q}_{\mathrm{ST}}\right)$ com o aumento da umidade de equilíbrio, ou seja, quanto menor a umidade da palma forrageira enriquecida proteicamente mais energia

Tabela 4. Resultado das regressões lineares das curvas do calor isostérico de adsorção para cada umidade de equilíbrio $\left(X_{\text {eq }}\right)$

\begin{tabular}{|c|c|c|c|c|c|c|}
\hline$x_{\text {eq }}$ & $30^{\circ} \mathrm{C}$ & $\frac{a_{w}}{35^{\circ} \mathrm{C}}$ & $40^{\circ} \mathrm{C}$ & inclinação & $\mathbf{R}^{2}$ & $\begin{array}{c}Q_{\text {st }} \\
\left(\mathbf{k J} \mathrm{kg}^{-1}\right)\end{array}$ \\
\hline 0,02 & 0,220 & 0,229 & 0,256 & $-1434,015$ & 0,963 & 662,228 \\
\hline 0,03 & 0,340 & 0,340 & 0,381 & $-1063,409$ & 0,864 & 491,082 \\
\hline 0,04 & 0,418 & 0,436 & 0,460 & $-921,804$ & 0,996 & 425,689 \\
\hline 0,05 & 0,482 & 0,493 & 0,522 & $-762,116$ & 0,969 & 351,945 \\
\hline 0,06 & 0,541 & 0,555 & 0,570 & $-500,82$ & 0,999 & 231,279 \\
\hline 0,08 & 0,622 & 0,645 & 0,651 & $-437,38$ & 0,954 & 201,982 \\
\hline 0,10 & 0,690 & 0,708 & 0,719 & $-395,186$ & 0,990 & 182,497 \\
\hline 0,12 & 0,738 & 0,760 & 0,765 & $-342,630$ & 0,943 & 158,226 \\
\hline 0,14 & 0,780 & 0,806 & 0,806 & $-316,110$ & 0,875 & 145,980 \\
\hline 0,16 & 0,816 & 0,838 & 0,836 & $-226,673$ & 0,820 & 104,678 \\
\hline 0,17 & 0,833 & 0,854 & 0,851 & $-205,899$ & 0,816 & 95,084 \\
\hline 0,18 & 0,849 & 0,868 & 0,862 & $-153,056$ & 0,708 & 70,681 \\
\hline 0,20 & 0,874 & 0,887 & 0,885 & $-120,616$ & 0,782 & 55,700 \\
\hline
\end{tabular}

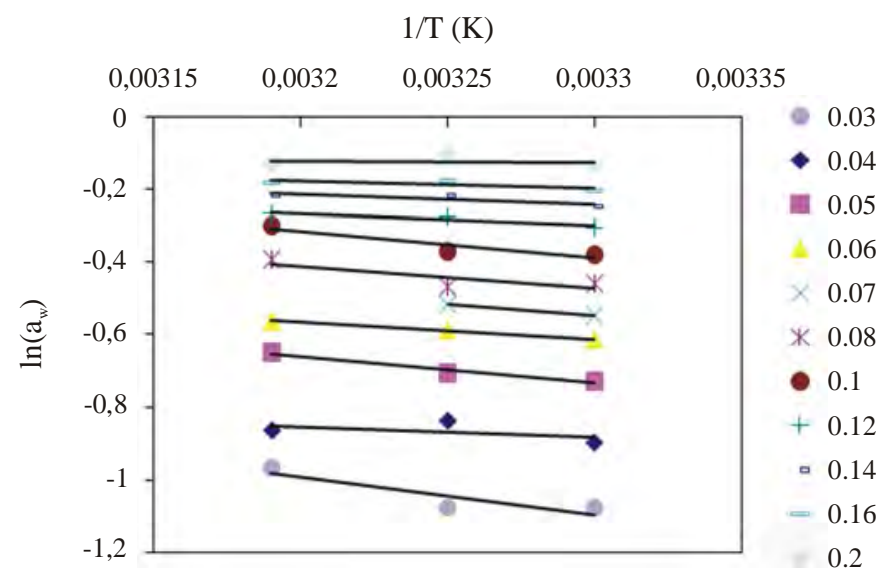

Figura 3. Curvas de $\ln \left(a_{w}\right)$ versus $1 / T$, baseadas na equação de ClausiusClapeyron, para diferentes níveis de umidade 
é requerida para evaporar a água ligada à estrutura biológica do produto, isto é, a evaporação de água da palma enriquecida requer energia para superar o calor de evaporação da água pura, sendo baixa a altas umidades e aumentando a baixas umidades.

Resultados e tendências semelhantes foram encontrados por Silva et al. (2002) e Gouveia et al. (1999) ao estudarem isotermas de sorção e o calor isostérico em polpa de manga e gengibre sem casca, respectivamente.

Tem-se, na Figura 4, a representação do calor de adsorção em função da umidade de equilíbrio, obtida pela Eq. 4. Os parâmetros calculados para este modelo, foram: $\mathrm{A}=82,716, \mathrm{~B}=799,659$ e $\mathrm{C}=0,044$ com coeficiente de determinação de 0,980 . Com base nesses valores, diz-se que o modelo prediz, com precisão, os valores do calor de sorção na palma enriquecida proteicamente em função da umidade de equilíbrio. A proporcionalidade inversa do calor de sorção com a umidade de equilíbrio confirma o estudo de Iglesias \& Chirife (1976), que atribuíram este comportamento ao processo de sorção de umidade.

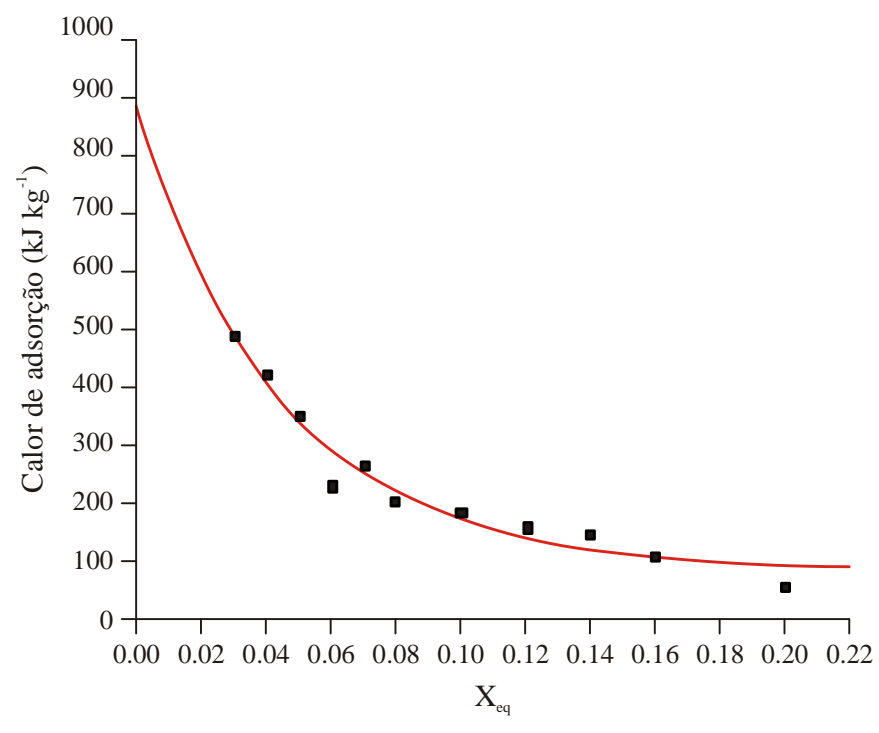

Figura 4. Calor isostérico de adsorção em função da umidade da palma forrageira enriquecida proteicamente, dados ajustados pela equação de Sopade \& Ajisegiri (1994)

\section{CONCLUSÕES}

1. As formas das isotermas de adsorção da palma forrageira enriquecida nutricionalmente, nas temperaturas de 30,35 e $40{ }^{\circ} \mathrm{C}$, seguem o tipo III da classificação de BET.

2. O modelo de Henderson foi o que melhor se ajustou aos dados experimentais das isotermas de adsorção, nas três temperaturas estudadas.

3. O calor isostérico de adsorção da palma forrageira enriquecida, diminui com o aumento da umidade de equilíbrio.

\section{LITERATURA CITADA}

Adam, E.; Myhlbauer, W.; Esper, A.; Wolf, W. F.; Spiess, W. Effect of temperature on water sorption equilibrium of onion (Allium cepa L.). Drying Technology, v.18, n.9, p.2117-2129, 2000.

AOAC - Association of Official Analytical Chemists. Official methods of analysis. 12.ed. Washington: AOAC, 1990. 1115p.

Araújo, L. F; Oliveira, L. S. C.; Perazzo Neto, A.; Alsina, O. L. S.; Silva, F. L. H. da. Equilíbrio higroscópico da palma forrageira: Relação com a umidade ótima para fermentação sólida. Revista Brasileira de Engenharia Agrícola e Ambiental, v.9, n.3, p.379-384, 2005.

Barros Neto, B.; Scarmínio, J. S.; Bruns, R. E. Planejamento e otimização de experimentos. Campinas: UNICAMP, 1995. 299p.

Batista Filho, M. Consumo de palma atenua carência de vitamina A. http://www.barney1.hpg.ig.com.br/palma.html. 07 Fev. 2005.

Blahovec, J. Sorption isotherms in materials of biological origin mathematical and physical approach. Journal of Food Engineering, v.65, n.4, p.489-495, 2004.

Brunauer, S.; Emmett, P.; Teller, E. Adsorption of gases in multimolecular layers. Journal of American Chemical Society, v.60, n.2, p.309-319, 1938.

Cavalcante, A. C. R.; Cândido, M. J. D. Alternativas para aumentar a disponibilidade de alimentos nos sistemas de produção a pasto na região Nordeste. Embrapa Caprinos, 31p. 2003. Documentos 47

Ferreira, C. D.; Pena, R. S. Comportamento higroscópico da farinha de pupunha (Bactris gasipaes). Ciência e Tecnologia de Alimentos, v.23, n.2, p.251-255, 2003.

Gabas, A. L. Secagem de uva Itália em leito fixo. Campinas: UNICAMP, 1998.135p. Dissertação Mestrado

Gouveia, J. P. G. de; Almeida, F. de A. C.; Fonseca, K. S.; Fernandez, F. R.; Murr, F. E. X. Estudo das isotermas de sorção e calor isostérico do gengibre em casca. In: Congresso Brasileiro de Engenharia Agrícola, 28, 1999, Pelotas. Resumos... Jaboticabal: SBEA, 1999, CD Rom.

Henderson, S. M. A basic concept of equilibrium moisture. Agricultural Engineering, v.33, n.1, p.29-32, 1952.

Iglesias, H.; Chirife, J. Prediction of the effect of temperature on water sorption isotherms of food material. Journal of Food Technology, v.11, p.109-116, 1976.

Kechaou, N.; Maalej, M. Desorption isotherms of imported banana. Drying Technology, v.17, n.6, p.1201-1213, 1999.

Labuza, T. P. Sorption phenomena in foods. Food Technology, v.22, n.3, p.263-274, 1968.

Lomauro, C. J.; Bakshi, A. S.; Labuza, T. P. Evaluation of food moisture sorption isotherm equations. Part I: Fruit, vegetable and meat products. Lebensmittel-Wissenschaft \& Techonologies, v.18, n.2, p.111-117, 1985.

Park, K. J.; Nogueira, R. I. Modelo para ajuste de isoterma de sorção de alimentos. Revista Engenharia Rural, n.3, v.1, p.80-86, 1992.

Perazzo Neto, A. Determinação de parâmetros para o enriquecimento protéico da palma (Opuntia fícus-indica) e vagens de algaroba (Prosopis juliflora) com Aspergillus niger. 152p. Rio de Janeiro: UFRJ, 1999. Tese Doutorado 
Santos, D. C.; Farias, I.; Lira, M. A. Palma forrageira (Opuntia ficus-indica Mill e Nopalea cochenillifera Salm-Dyck) em Pernambuco; cultivo e utilização. Recife: IPA, 23p. 1997. Documentos 25

Santos, M. V. F.; Lira, M. A.; Farias, I. Estudo comparativo das cultivares de palma forrageira gigante, redonda (Opuntia ficusindica Mill) e miúda (Nopalea cochenillifera Salm-Dyck) na produção de leite. Revista Brasileira de Zootecnia, v.19, n.6, p.504-511, 1990.

Santos, M. V. F.; Lira, M. A.; Farias, I. Efeito do período de armazenamento pós-colheita sobre o teor de matéria seca e composição química das palmas forrageiras. Pesquisa Agropecuária Brasileira, v.27, p.777-783, 1992.

Silva, M. M. da; Gouveia, J. P. G. de; Almeida, F. de A. C. Dessorção e calor isostérico em polpa de manga. Revista Brasileira de Engenharia Agrícola e Ambiental, v.6, n.1, p.123-127, 2002.
Sopade, P. A.; Ajisegiri, E. S. Moisture sorption study on nigerian foods: Maize and sorghum. Journal of Food Process Engineering, v.17, n.1, p.33-56, 1994.

Teixeira, J. C.; Evangelista, A. R.; Perz, J. R.; Trindade, I. A. C. M.; Moron, I. R. Cinética da digestão ruminal da palma forrageira. Ciência e Agrotecnologia, v.23, n.1, p.179-183, 1999.

Tolaba, M. P.; Suarez, C. Simulation of the thin-layer drying of corn by means of the diffusion model. LebensmittelWissenschaft und Technologie, v.21, n.2, p.83-85, 1995.

van den Berg, C. Development of BET like models for sorption of water of food: Theory and relevance. In: Simatos, D.; Milton, J. L. (ed.). Properties of water foods. Dordrecht: Mastinua Nyhoff Publishers, 1985. p.119-131.

Wang, N.; Brennan, J. G. Moisture sorption isotherm characteristics of potato at four temperatures. Journal of Food Engineering, v.14, p.269-287, 1991. 